Article

\title{
Development of a Resilient 3-D Printer for Humanitarian Crisis Response
}

\author{
Benjamin L. Savonen ${ }^{1}$, Tobias J. Mahan ${ }^{1}$, Maxwell W. Curtis ${ }^{2}$, Jared W. Schreier ${ }^{2}$, \\ John K. Gershenson ${ }^{3}$ and Joshua M. Pearce ${ }^{4,5,6, * \text { (iD }}$ \\ 1 Department of Mechanical and Nuclear Engineering, The Pennsylvania State University, \\ State College, PA 16801, USA; bls78@psu.edu (B.L.S.); tjm450@psu.edu (T.J.M.) \\ 2 Department of Mechanical Engineering, Michigan Technological University, Houghton, MI 49931, USA; \\ mwcurtis@mtu.edu (M.W.C.); jwschrei@mtu.edu (J.W.S.) \\ 3 Humanitarian Engineering and Social Entrepreneurship Program, The Pennsylvania State University, \\ State College, PA 16801, USA; jzg322@psu.edu \\ 4 Department of Electronics and Nanoengineering, School of Electrical Engineering, Aalto University, \\ 02150 Espoo, Finland \\ 5 Department of Materials Science \& Engineering, Michigan Technological University, \\ Houghton, MI 49931, USA \\ 6 Department of Electrical \& Computer Engineering, Michigan Technological University, \\ Houghton, MI 49931, USA \\ * Correspondence: pearce@mtu.edu; Tel.: +1-906-487-1466
}

Received: 12 February 2018; Accepted: 1 March 2018; Published: 9 March 2018

\begin{abstract}
Rapid manufacturing using 3-D printing is a potential solution to some of the most pressing issues for humanitarian logistics. In this paper, findings are reported from a study that involved development of a new type of 3-D printer. In particular, a novel 3-D printer that is designed specifically for reliable rapid manufacturing at the sites of humanitarian crises. First, required capabilities are developed with design elements of a humanitarian 3-D printer, which include, (1) fused filament fabrication, (2) open source self-replicating rapid prototyper design, (3) modular, (4) separate frame, (5) protected electronics, (6) on-board computing, (7) flexible power supply, and (8) climate control mechanisms. The technology is then disclosed with an open source license for the Kijenzi 3-D Printer. A swarm of five Kijenzi 3-D printers are evaluated for rapid part manufacturing for two months at health facilities and other community locations in both rural and urban areas throughout Kisumu County, Kenya. They were successful for their ability to function independently of infrastructure, transportability, ease of use, ability to withstand harsh environments and costs. The results are presented and conclusions are drawn about future work necessary for the Kijenzi 3-D Printer to meet the needs of rapid manufacturing in a humanitarian context.
\end{abstract}

Keywords: 3-D printing; additive manufacturing; disaster relief; distributed manufacturing; open hardware; open source hardware; humanitarian engineering; humanitarian logistics; rapid manufacturing; remote manufacturing

\section{Introduction}

With some of the largest refugee crises in human history currently occurring, the need for fast and effective disaster relief is now more important than ever. The United Nations Office for the Coordination of Humanitarian Affairs (UNOCHA) estimates that 164.2 million people on the planet received some form of humanitarian assistance during 2016 [1] and that number is likely to grow in coming years. The core of any humanitarian response to a disaster (natural or man-made) is a logistical effort to move goods from where they are available to where an affected population is located $[2,3]$. 
Yet, supply chain logistics for humanitarian responses are some of the most complex that exist. It is challenging to forecast both the demand (due to difficulties in knowing both the timing of a disaster and details of the population affected) and the supply, which is often fueled by donations [4]. A massive mismatch between the supplies delivered and the supplies that are needed is often inevitable both in quantity and kind $[2,3,5]$. As $60-80 \%$ of all aid money is spent on procurement, this mismatch represents not only costly errors but errors that can have negative long-term effects on local markets and economies [5].

Rapid manufacturing using 3-D printing is a potential solution to some of these pressing issues in humanitarian logistics. This has become potentially feasible with the open source 3-D printers developed from the self-replicating rapid prototyper (RepRap) project [6-8]. The RepRap project has driven down costs of 3-D printing to fit resource-constrained contexts like those found in the developing world or during a crisis [9]. The potential for 3-D printers in humanitarian aid work has been able to capture the interest of practitioners in the field [10], as 3-D printing can have positive effects on nearly every step of the humanitarian supply chain [5].

$3-\mathrm{D}$ printing can reduce time and money used in the procurement of goods [11,12] by reducing the amount of capital required for manufacturing at a given location, allowing distributed manufacturing [13-15] or more localized manufacturing to occur [3,10]. By manufacturing goods locally at the site of a disaster response, the only materials that need to be shipped to the site of a disaster are the raw materials needed for manufacturing. These raw materials typically take up far less storage and transport space, are far more durable and require far less packaging than the actual goods needed in a disaster response $[2,3,16]$. It is straight-forward to power the devices with solar photovoltaic technology so that rapid manufacturing can take place on site without reliable power $[17,18]$.

The on-demand fabrication of parts allowed by 3-D printing can also help to reduce the mismatch of what is needed in a crisis and what is supplied. Many relief organizations ship thousands of items that are not required and find they require many that were not shipped. The International Committee of the Red Cross and Red Crescent (ICRC), for example, has a set catalog of nearly 10,000 different items that it ships to any given disaster [19]. 3-D printing cannot only be used to only manufacture the exact designs required but also allow a degree of local customization previously impossible. This customization can take many forms, including optimizing designs to match a user's geometry [20] or adapting a part to fit a specific machine [2,5]. The use of 3-D printing has already begun to be looked into by Oxfam [21] and the American Red Cross [22,23], as well as in military and space exploration scenarios [24]. 3-D printing has been found to be useful in addressing humanitarian response needs as diverse as housing [25], vehicle repair [4], surgical tools [26] and malnutrition identification bands [27].

Two non-governmental organizations (NGOs) in particular have been exploring the possibilities with 3-D printing-Field Ready [28] and Refugee Open Ware (ROW) [29]. Field Ready explores different ways of localizing the manufacturing of items needed in a crisis, especially with digital fabrication methods. Through trials in Haiti, Nepal, Syria and several other countries, they have used 3-D printing to create items for water access, sanitation, health, camp management, shelter, nutrition, protection, education, logistics, telecommunication and early recovery efforts [5]. ROW brings digital fabrication tools and training to refugees from Syria, so that refugees begin to develop their own supplies and the skills to address the challenges of rebuilding their lives. While much of what ROW has produced are prosthetics, refugees that work with ROW have also developed a variety of products to address other challenges faced by Syrian refugees, including water management and blindness [29]. Although current 3-D printing technology cannot completely replace traditional logistics, by integrating 3-D printing into a humanitarian response, the larger relief effort can be made much more efficient and the mismatch can be reduced [5,30].

Although the attention on 3-D printing is ever increasing in humanitarian circles, there are currently no 3-D printers designed and manufactured for this market [31]. All trials and instantiations of 3-D printing for humanitarian efforts have relied upon small desktop 3-D printers, due to their smaller size, lower cost and relative simplicity of use [5]. While these machines perform relatively consistently 
in controlled conditions, the conditions in which humanitarian work takes place are typically very unpredictable with regards to the physical environment, public infrastructure, telecommunication abilities and socio-political stability [32]. Desktop printers are not designed for this context and their already high level of unreliability is exacerbated in these unstable settings [31]. There is, thus, a definite need for a robust, easily deployable printer designed for adapting to the many contextual challenges associated with humanitarian response work $[3,5,10,31]$. This study seeks to provide such a means of rapid manufacturing in the humanitarian disaster context. First, the required capabilities are developed, which provide guidelines for the design elements of a humanitarian 3-D printer, which included, (1) fused filament fabrication (FFF), (2) open source RepRap, (3) modular, (4) separate frame, (5) protected electronics, (6) on-board computing, (7) flexible power supply, and (8) climate control mechanisms. These capabilities are then disclosed here with an open license for the Kijenzi 3-D Printer. The Kijenzi 3-D Printer is then evaluated for rapid part manufacturing, ability to function independently of infrastructure, transportability, ease of use, ability to withstand harsh environments and costs. The results are presented and discussed and conclusions are drawn about the capacity for the Kijenzi 3-D Printer to meet the needs of rapid manufacturing in the humanitarian context.

\section{Materials and Methods}

\subsection{Required Capabilities of a Humanitarian 3-D Printer}

Existing literature details six recurring themes concerning the future use of 3-D printing in humanitarian response or other similarly austere situations. These themes are reframed as desired capabilities that any 3-D printer must possess to maximize utility in these contexts. We then used these six capabilities to identify eight design elements that could be incorporated into a prototype 3-D printer. This printer was then tested in Western Kenya for two months in order to assess the ability of the design elements to meet the required capabilities.

\subsubsection{The 3-D Printer Must Be Able to Make Useful Parts}

A 3-D printer is only as useful as the products that it is able to make, therefore any 3-D printer used in humanitarian response must be able to reliably and efficiently make high-functioning, customizable parts that are relevant to disaster-type situations $[2,3,5,33]$. In order to accommodate as many of the diverse needs that may arise in a humanitarian crisis as possible, a 3-D printer should be able to manufacture a large range of product sizes $[2,10,31,34]$ and with as many materials as is possible $[2,31]$.

\subsubsection{The 3-D Printer Must Be Able to Function Independent of Infrastructure}

Due to unreliable infrastructure and supply chains present during humanitarian crises, a 3-D printer must be able to reliably function with minimal external support. This must include being able to operate in settings with minimal to no power sources $[2,3,5,10,35,36]$ or telecommunication connections $[10,16]$. In the event of the machine failing, it should be able to be easily repaired with locally available parts, materials and tools, as supply chains are inherently unreliable [2,33-35].

\subsubsection{The 3-D Printer Must Be Able to Be Easily Transported}

As transportation situations and infrastructure are often compromised during humanitarian crises, it is important that the 3-D printer designed to be easily transported to anywhere within a crisis zone. This includes being both portable enough to accommodate a wide ranges of transportation types and be durable enough to not sustain damage during transportation $[5,31,33,34]$.

\subsubsection{The 3-D Printer Must Be Safe and Easy to Use}

As many the 3-D printers currently available require significant experience to maintain and operate, a 3-D printer designed for humanitarian crisis response must be able used by aid workers or displaced peoples with minimal training and a wide range of backgrounds $[2,3,35]$. This includes 
having reliable functionality, a user-centered interface, self-maintenance on the part of the machine and simplified troubleshooting [2,31], Further, in keeping with humanitarian principles, these machines should not produce any hazards for their operators, such as emitting harmful fumes [35], or having exposed heating elements.

\subsubsection{The 3-D Printer Must Be Able to Withstand Harsh Environments}

A 3-D printer designed for use in crisis scenarios must be able to reliably fabricate parts despite a variety of adverse environmental conditions including high/low temperatures [2,34], humidity [5,10,34], wind [10], dust [2,16,34] and unstable surfaces [10]. The 3-D printer should also not contribute negatively to the environment by creating excessive amounts of plastic waste or giving off harmful fumes [35].

\subsubsection{The 3-D Printer Must Be Able to Be Procured for Minimal Cost}

As budgets for humanitarian response are typically tight, it is important that the costs associated with procuring or deploying a 3-D printer be reduced as much as possible [31]. Any current instantiations of 3-D printing in humanitarian contexts are either improvised solutions that supplement off-the-shelf 3-D printers with other technologies to try to better meet some of these capabilities (Figure 1) or they must suffice with less resilient technology.

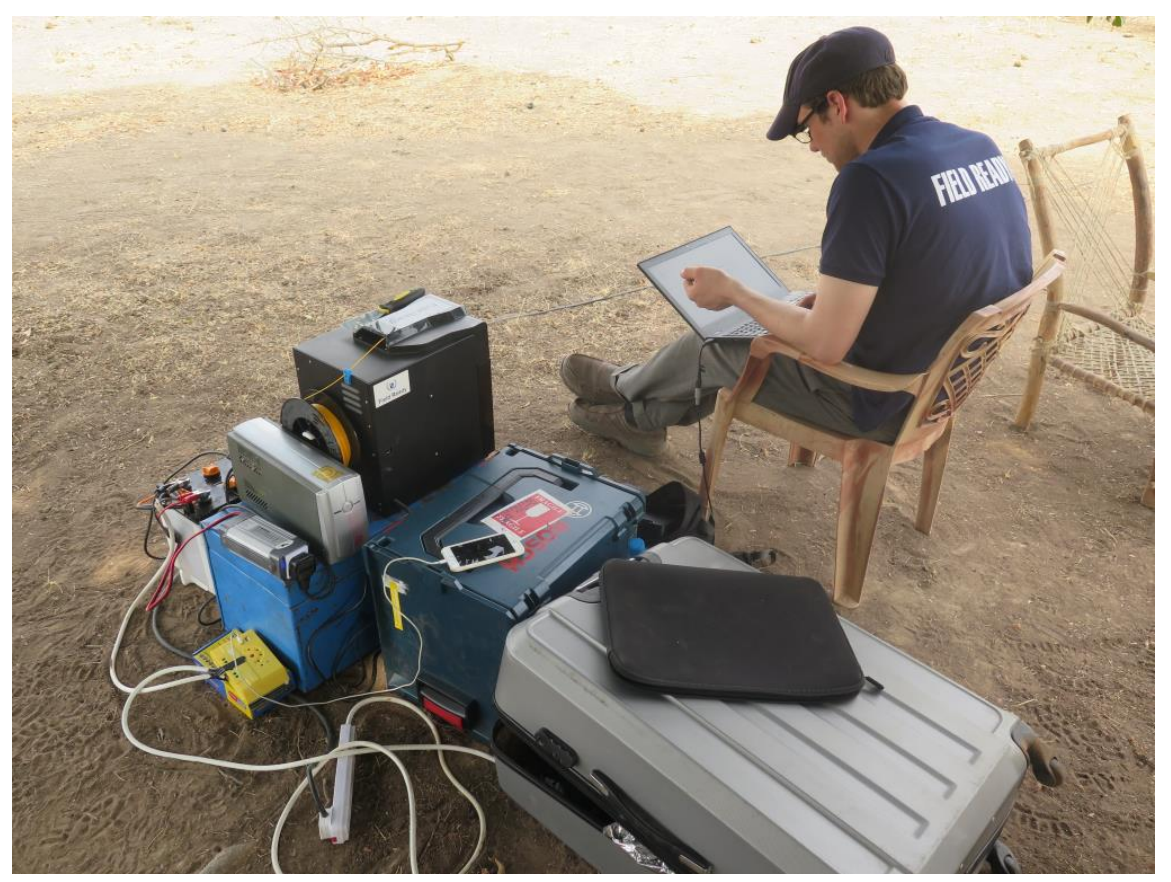

Figure 1. Field Ready 3-D Printer being supported with a variety of supplementary technologies in South Sudan (Photo Credit: Andrew Lamb, Field Ready).

\subsection{The Design of Humanitarian 3-D Printer}

To create a more capable 3-D printer, an initial set of eight design elements were identified for incorporating into a humanitarian 3-D printer first generation prototype. In Table 1, the six desired capabilities distilled from literature are compared to these eight design elements and we describe these eight elements in greater detail, how they affect the desired capabilities and how they were incorporated into a prototype 3-D printer. 
Table 1. Design elements for a humanitarian 3-D printer and how they relate to the desired design capabilities, an ' $\mathrm{X}$ ' indicates that the design element better enables a corresponding capability.

\begin{tabular}{|c|c|c|c|c|c|c|c|c|}
\hline \multirow[b]{2}{*}{ Desired Capabilities } & \multicolumn{8}{|c|}{ Design Elements } \\
\hline & $\begin{array}{l}\text { Fused Filament } \\
\text { Fabrication }\end{array}$ & $\begin{array}{l}\text { Open-Source } \\
\text { RepRap }\end{array}$ & $\begin{array}{c}\text { Modular } \\
\text { Design }\end{array}$ & $\begin{array}{l}\text { Separable } \\
\text { Frame }\end{array}$ & $\begin{array}{c}\text { Protected } \\
\text { Electronics }\end{array}$ & $\begin{array}{l}\text { Flexible Power } \\
\text { Supply }\end{array}$ & $\begin{array}{c}\text { On-Board } \\
\text { Computer System }\end{array}$ & $\begin{array}{c}\text { Environmental } \\
\text { Control }\end{array}$ \\
\hline Make Useful Parts & $x$ & & $x$ & $x$ & & & & $\mathrm{x}$ \\
\hline Function Independent of Infrastructure & & $\mathrm{x}$ & & & & $\mathrm{x}$ & $x$ & \\
\hline Easily Transported & & & & $\mathrm{x}$ & $\mathrm{x}$ & & & \\
\hline Easily Used & & $\mathrm{x}$ & $\mathrm{x}$ & & & & $\mathrm{x}$ & \\
\hline Withstand Harsh Environments & & & & & $\mathrm{x}$ & $\mathrm{x}$ & & $\mathrm{x}$ \\
\hline Procured for Minimal Cost & $\mathrm{x}$ & $\mathrm{x}$ & $\mathrm{x}$ & & & & & \\
\hline
\end{tabular}


After its construction, the 3-D printer prototypes were tested for two months in western Kenya to assess the validity of these design elements in achieving the desired capabilities. Five Kijenzi printers and 18 kilograms of 3-D printer filament of various thermoplastics was taken to Kisumu, Kenya. The 3-D printers were subjected to two months of being assembled and disassembled and transported to and from health facilities and other community locations in both rural and urban areas throughout Kisumu County.

Printers were used for demonstration and prototyping purposes at these facilities and then packed up every evening and brought to a central location in Kisumu town. These printers were transported, disassembled and in backpacks and duffle bags, over both tarmac and rough roads via taxi, motorcycle and minibus. One of the five printers was also subjected to additional airline and bus travel, transported across southern Uganda and Tanzania for additional demonstrations. Their performance was monitored and recorded with respect to meeting the six desired capabilities listed in Table 1.

\section{Results and Discussion}

Using the design elements in Table 1, a prototype 3-D printer, dubbed Kijenzi (loosely meaning 'little maker' in Swahili), was successfully designed and fabricated (Figure 2). The design elements are described in more detail and then evaluated in the following sections.

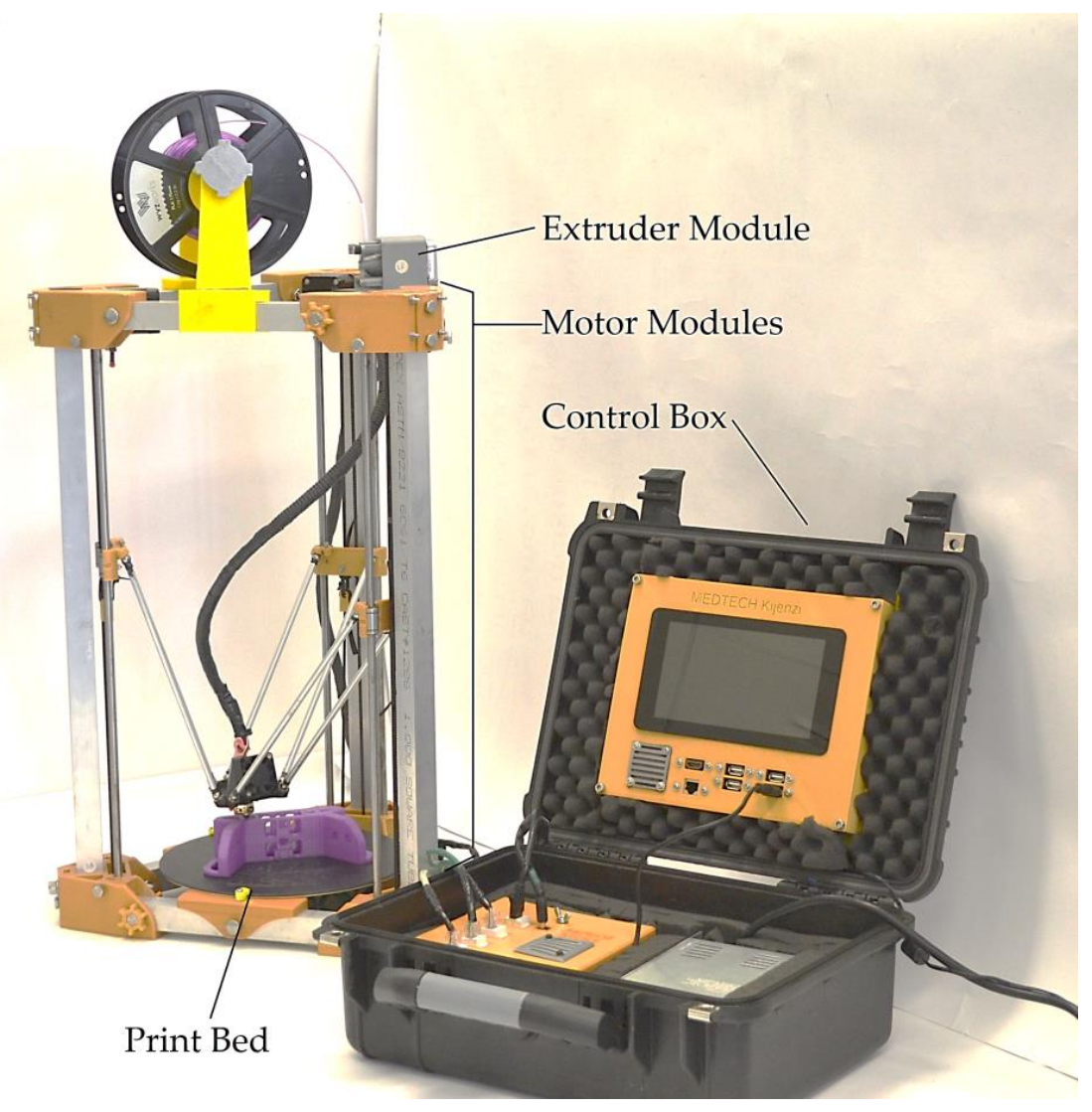

Figure 2. The Kijenzi 3-D printer prototype assembled and configured for operation.

\subsection{Design Elements}

The eight design elements include, (1) fused filament fabrication (FFF), (2) open source self-replicating rapid prototyper design, (3) modular, (4) separate frame, (5) protected electronics, (6) on-board computing, (7) flexible power supply, and (8) climate control mechanisms. Explanations of each element and their relation to the six required capabilities are detailed below. 


\subsubsection{Fused Filament Fabrication (FFF)}

FFF-based 3-D printing is the non-trademarked version of fused deposition modeling (FDM) and has come to dominate the 3-D printing market in volume of printers [37]. FFF-based 3-D printers based on the delta style design [38] operate by pushing molten thermoplastic through an end effector attached to a robotic arm (Figure 2). The robotic arm is programmed to move via gcode from slicer software, which in turn slices the geometry of the desired shape given in a Standard Tessellation Language (STL). The relative simplicity of this technology in comparison to other 3-D printing types renders it the most cost effective and reliable type of 3-D printing technology [2,33]. Able to manufacture with virtually any thermoplastic with acceptable mechanical properties [39], FFF can also create a more diverse array of products than most other 3-D printing technologies [2,33]. Thermoplastics have a wide variety of applications in many humanitarian sectors, especially in medical and health care devices and using an FFF 3-D printer will therefore maximize the number of useful parts that the Kijenzi can manufacture.

\subsubsection{Open-Source RepRap Design}

To further reduce costs, increase usability and minimize the reliance on specific infrastructure, it is necessary that the Kijenzi 3-D printer incorporate open-source designs. Many FFF-based 3-D printers are built with open-source elements developed by a global community of user-experts in the RepRap community and the rapid growth of 3-D printing over the past decade has largely been attributed to its open-source nature [40]. By building a prototype with these widely available and accessible designs and components, users of the Kijenzi printer will be able to more freely access all of the information and support needed for successful operation and maintenance [12]. Self-replicating rapid prototypers are open-source 3-D printers designed to be able to fabricate many of their own components [6-8]. This ability reduces the production cost of a RepRap machine when compared to other printers and also allows for the manufacturing of spare and replacement parts on one 3-D printer for use on another, which is particularly useful when operating 3-D printers in remote or rural areas. Creating spare parts allows for increased self-sufficiency when access to conventional supply chains becomes difficult and can often reduce both time and financial expenses [33].

The Kijenzi printer was created with completely open-source hardware and software and in the spirit of open-source, its design is made freely available with an open source GNU General Public License (GPL) 3.0 [41] (GNU is a recursive acronym for "GNU's Not Unix!", chosen because GNU's design is similar to Unix, but contains no Unix code and is free software). All of the components of the Kijenzi are either readily available as off-the-shelf components or are 3-D printable on another FFF printer. Currently the Kijenzi printer can produce 18 of its 98 parts. When designing the Kijenzi prototype, elements of pre-existing RepRap designs, especially the delta style Athena/MOST RepRap [38]. By continuing the development of the Kijenzi printer with only open-source designs and hardware, its future development can be furthered by others in the 3-D printing community.

Delta-style printers, with their three parallel axes of motion, are not used by the majority of the 3-D printing community, as they are generally more complicated to calibrate and occupy more space that is unusable as a build volume. This problem of unused build space was made irrelevant by the Kijenzi's ability to be collapsed as discussed below. The complexity of the calibration process was also disregarded as it was determined that the calibration process could be automated in future prototypes and thus the user would not have to experience this complexity. The delta-style printer is preferable as it generally has a smaller end effector, is able to obtain faster printing speeds and has a greater degree of frame symmetry than Cartesian-style printers. The increased symmetry provided by having three identical towers in a delta-style 3-D printer requires fewer unique components, which is advantageous as this results in fewer non-printable spare parts that may need to be transported along with the printer during deployment. 


\subsubsection{Modular Design}

Modularity is one of the most important design elements to be incorporated into a humanitarian 3-D printer [10], as increased modularity can equate to increased adaptability in terms of contexts, users and finances. Modularity allows for an easier upgrade in functionalities, expanding the types of parts that a 3-D printer can fabricate. Modularity can also result in easier downgrades to accommodate budgets, simplicity, or robustness. A design with highly modular components can also be easier for users to repair, as both components and modules will be easier to replace.

This effect of modularity also presents unique advantages when using several Kijenzi printers in conjunction with one another in a 3-D printer 'swarm'. When doing so, the 3-D printer is no longer just a singular tool but becomes a system of printers and modules that can be interchanged to optimize the productivity across the swarm and achieve specific rapid manufacturing capabilities. If one printer fails, it can freely take modules from other printers to quickly restore functionality, or the fully-functioning modules of several failed printers can be used to quickly assemble an additional working printer. Further, if a Kijenzi printer is configured to print one particular type of part but would benefit from an upgraded module present on a different printer, the modules can be traded across the system of Kijenzi printers to optimize the quality of the parts being printed.

The Kijenzi printer was divided into six major modules: Alpha Motor Module, Beta Motor Module, Gamma Motor Module, Extruder Module, Print Bed, and Control Box. Each of the six modules were able to be attached or detached from the main assembly by hand and without any tooling. They can all be seen in Figure 3. This modularity was further increased by the symmetry of the delta-style 3-D printer, as Alpha, Beta, and Gamma motor modules are all interchangeable with one another. There are therefore only four unique modules on any given Kijenzi printer.

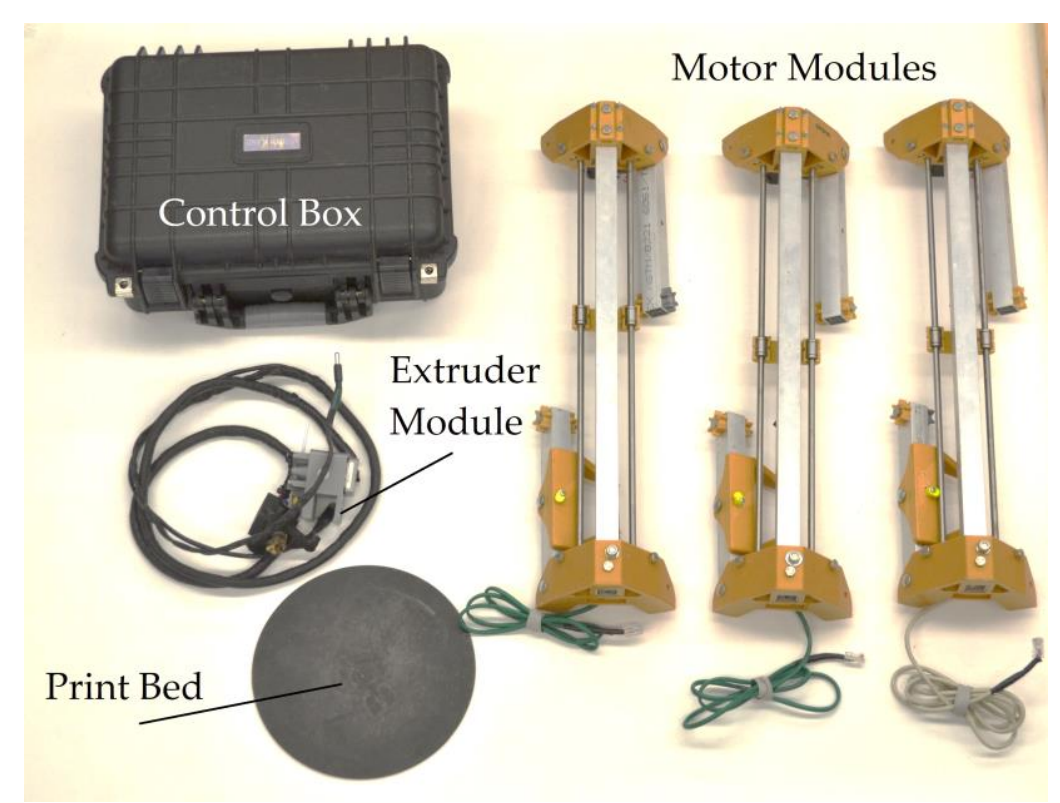

Figure 3. The Kijenzi divided into modules and labeled.

The Alpha, Beta, and Gamma Motor Modules together made up the main frame of the Kijenzi printer and worked in conjunction to provide the motion of the end effector. The Extruder Module is comprised of both an end effector capable of heating and depositing the molten thermoplastic and a stepper motor assembly for feeding filament to the end effector through a tubing system. The Print Bed attaches to the bottom of the three motor modules and forms the platform that molten filament would be deposited onto in order to form the desired part. All of these modules connect together at the Control Box, the module that supplies all of the other modules with power. 
By creating multiple forms of the Extruder Module, Print Bed, and Control Box, the printer can be easily upgraded by merely trading out any of these modules to accommodate different build-material types or electrical sources. For example, an upgraded Print-Bed Module with a heated platform and an Extruder Module with a dual-fan end effector can be used on the Kijenzi 3-D printer frame to allow for fabrication with higher-strength materials like nylon (Figure 4).
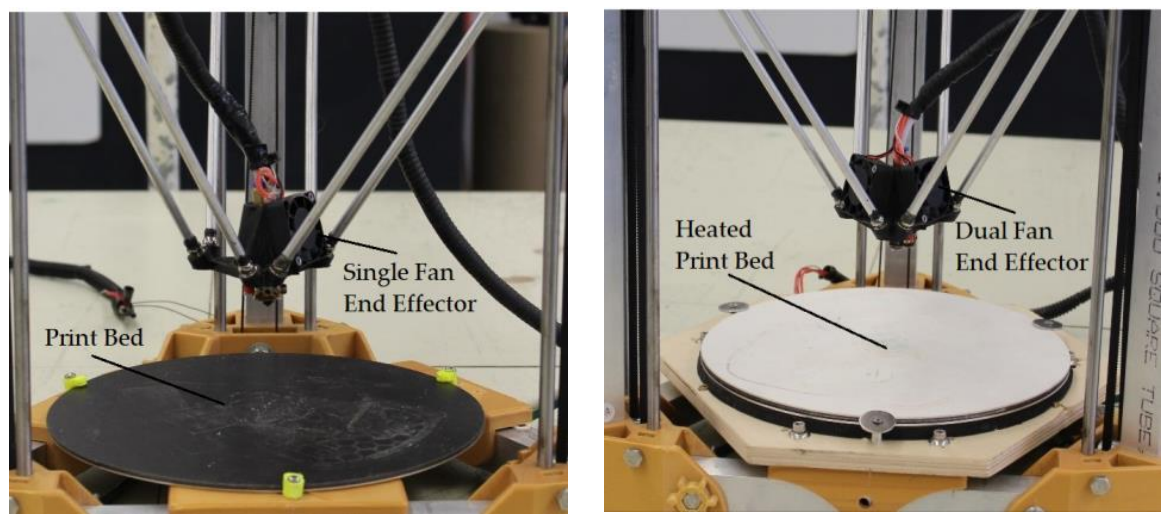

Figure 4. Comparison of the base Kijenzi design (left) and upgraded features for higher temperature materials (right).

\subsubsection{Separable Frame}

Creating a transporTable 3-D printer presents unique spatial challenges. 3-D printers typically maximize their build volume (the space in which parts are fabricated) to maximize the size of parts which they are able to produce. During transport, however, this quickly becomes problematic, as a 3-D printer's packaging will inherently include the empty space of that build volume. By incorporating a degree of collapsibility into the design, portability can be maximized, without compromising on the size of the build volume or size of the parts the Kijenzi is able to fabricate.

There are already several designs available for transporTable 3-D printers [18] in addition to commercial units that usually involve a backpack strap attached to a box style Cartesian printer, but the build volumes of these printers are generally smaller (e.g., the FoldaRap [42]) than other desktop 3-D printers. The modularity of the Kijenzi printer directly contributes to its transportability. While the other 3-D printers designed for transportability are in some cases created to be foldable, there was no specific advantage found that foldability offered over modular disassembly in regard to ease of transportation. Thus, by building off of the modularity already incorporated into the design, the Kijenzi printer was made to be easily packable as shown in Figure 5.

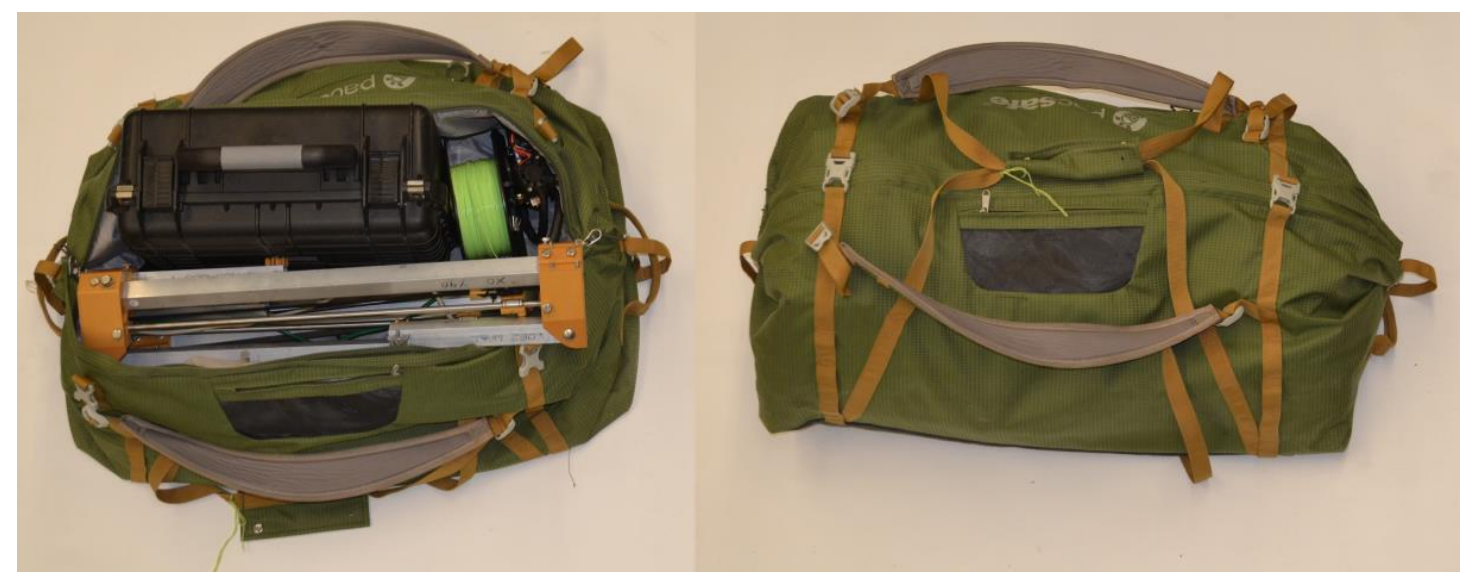

Figure 5. The Kijenzi 3-D printer can be disassembled and fit into a backpack or travel duffle. 
By designing the Kijenzi to separate into modules during travel rather than folding, the modules can move freely relative to one another during transport, have fewer rigid points where failures may occur and the overall fragility of the system is reduced. Additionally, fully separable modules can be more easily packed into a variety of container types, whereas a folding 3-D printer design would not have the same packing flexibility.

The frame of the Kijenzi printer is made up of three interchangeable Alpha, Beta, and Gamma Motor modules. These modules are $609.6 \mathrm{~mm}$ ( $24 \mathrm{inch}$ ) towers comprised of two 3-D-printed corner brackets connected by $25.4 \mathrm{~mm}$ ( 1 inch) square aluminum tubing and $8 \mathrm{~mm}$ A2 tool-steel rods. A stepper motor and mechanical switch are mounted on the top corner bracket and a toothed belt connects the axle of the stepper motor to bearings mounted on bottom corner bracket. This motor-driven belt moves a carriage, mounted to the tool-steel rods by way of linear bearings and is able to move from the top to the bottom of the tower. Each corner bracket (top and bottom) also has an additional arm of aluminum tubing that allows the three motor modules to connect to one another. Figure 6 shows a close-up of a motor module, with each of the major components highlighted.

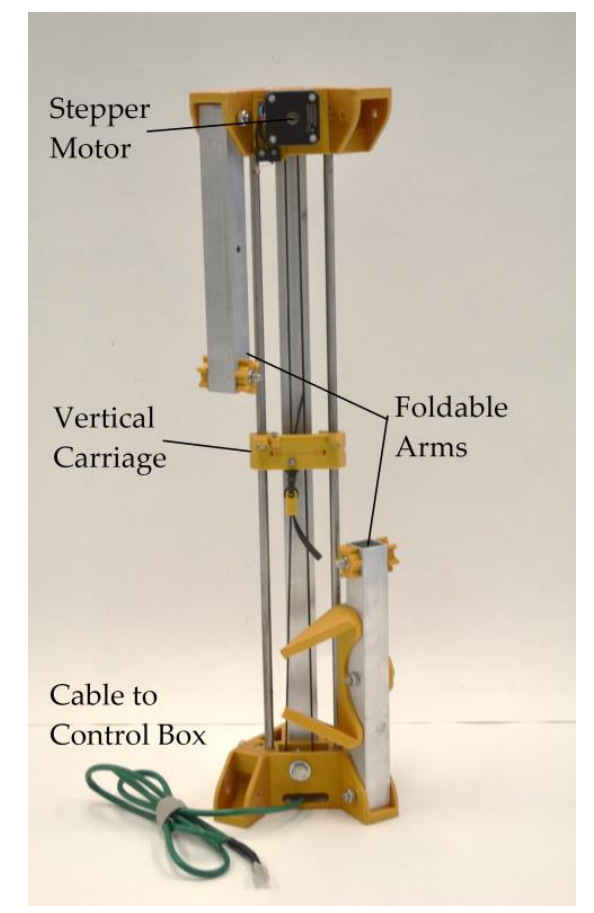

Figure 6. The motor module of the Kijenzi 3-D printer with key components labeled.

\subsubsection{Protected Electronics}

As the electronics represent both the most expensive and vulnerable components on nearly any 3-D printer, being able to isolate all of the key electronic components improves their security during both usage in adverse environments and transportation to these environments. For the Kijenzi printer a padded, watertight, plastic casing was placed around the electronics. These electronics include, a Smoothieboard 5X (an open-source 3-D printer control board and computer processing unit), a 24 volt power supply unit, multiple cooling fans and the on-board computer system discussed next. During the operation of Kijenzi the case remains open (Figure 7) and the other modules are all able to be clipped into the Control Box through Ethernet cables. Each of the other modules have their respective loads and sensors routed through a singular Ethernet cable that can be attached to the Control Box (highlighted in Figure 8). The one exception to this is the end-effector's heater, which is connected through a $2.5 \mathrm{~mm}$ barrel connector, as its load requires current unable to be carried through the Ethernet cables. 


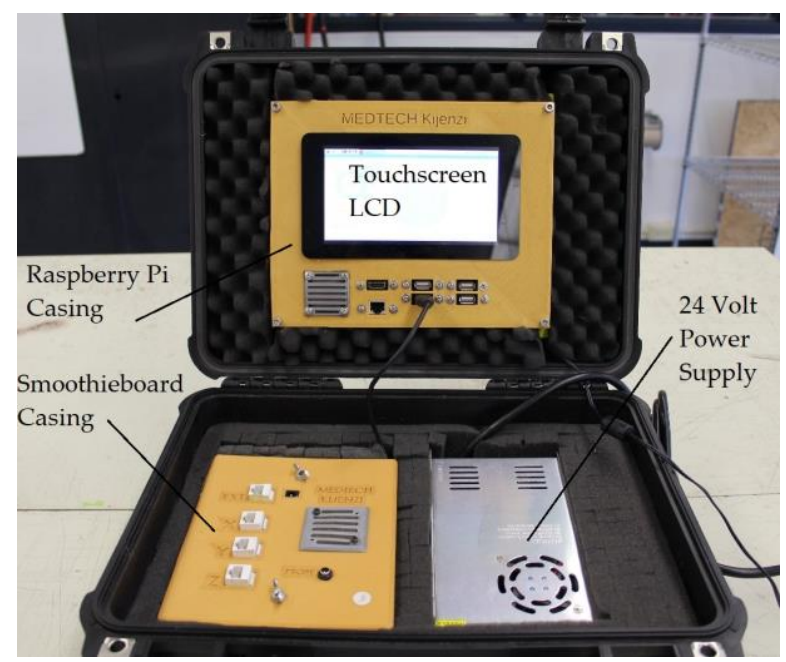

Figure 7. The Control Box for the Kijenzi 3-D printer with Liquid Crystal Display (LCD).

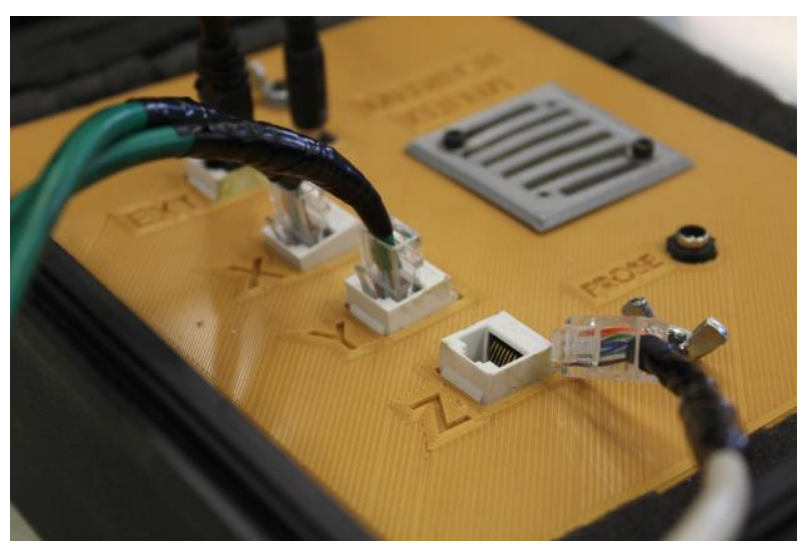

Figure 8. Sensors, Motors, Heaters and Fans all clipped into the Control box via Ethernet cables.

The ability of each module to quickly clip in and out of the Control Box removed the need for any wiring or soldering of electrical components when attaching or changing a module to the Control Box. In addition to resulting in improved modularity, this system allowed for improved transportability, as the Kijenzi printer could be quickly disassembled for transportation without any of the wiring or electronics ever becoming exposed.

\subsubsection{On-Board Computer System}

Many 3-D printers require a connection to a computer either before or during the printing process and this requirement results in an added layer of system complexity when it comes to 3-D printing independent of infrastructure. If there is a computer that has not previously been used with the 3-D printer, it must go through a configuration process, possibly be tethered to the printer and have its own reliable power source. By integrating the computer directly into the 3-D printer, the entire system can be less expensive, more independent and simplified, eliminating the need for an external computer and the accompanying risks presented in protecting and maintaining another piece of equipment.

Within the electronics case of the Kijenzi printer, we included a separate Raspberry Pi with a Linux-Debian-based operating system that was especially configured for use on a Raspberry Pi [43] and a 3.5 by 6 inch touchscreen (Figure 9). At $\$ 115$, this solution was significantly less expensive than using any laptop to control the printer, which would have also required additional transportation considerations and uses $20-30 \mathrm{~W}$ of power during printing compared to the $4-7 \mathrm{~W}$ used by the Raspberry Pi and touch screen during printing. This on-board computer was outfitted with only the 
software for configuring and controlling the 3-D printer and 1 gigabyte of storage for holding many STL files and the gcode files used during 3-D printing. This also allows for a singular power set up for both-so we can control off grid power now that we know the exact draw of the entire system with computer included.

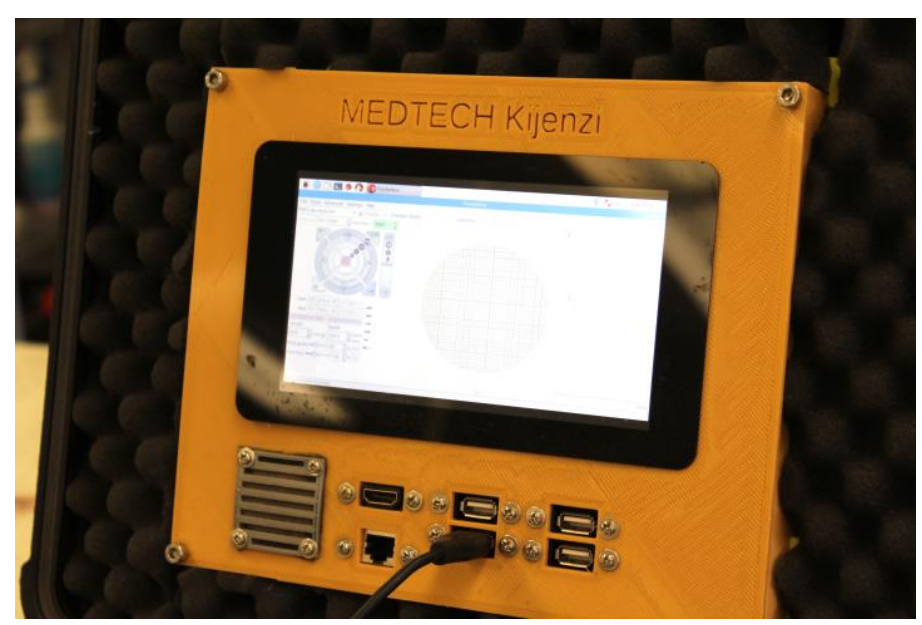

Figure 9. Close-up of the on-board computer.

\subsubsection{Flexible Power Supply}

Access to electricity can vary greatly across both developing world contexts and disaster response scenarios and nearly all of the literature on 3-D printing in remote environments highlight the importance of a 3-D printer being able to be flexible in the power sources that it draws from $[2,3,5,10,34]$. The ability to have a power source that can consistently provide power at all times is critical to creating a printer that can function independently and in any environment regardless of the presence of any electrical infrastructure. To protect the electronics components of the 3-D printer, a separate power supply unit to regulate the input current and voltage supplied to the main control board is included. This unit is able to be switched between 110 volts and 220 volts inputs depending on the country in which it is being used. This unit is also integrated with the other electronics in the Control Box.

While this solution may prove useful in protecting the other electronics in the Control Box, it does not yet improve the ability of the Kijenzi to continue operation during a power outage or enable printing in locations where no power is yet available. However, as other power sources such as batteries, solar photovoltaic modules, or generators are considered to address these challenges, the power supply unit will be able to easily integrate these solutions while regulating a constant power supply to the 3-D printer electronics and on-board computer.

\subsubsection{Climate Control Mechanisms}

3-D printers, like other electronic devices, are susceptible to damage from dust, humidity and extreme temperatures. However, the process of fabricating parts with 3-D printing is also sensitive to environmental factors, as adverse conditions can affect the quality of the parts the 3-D printer produces. Establishing climate control mechanisms within the 3-D printer is necessary for ensuring the continued quality of the machine and the parts that it produces. To help with cooling, fans were placed on the on-board computer, the main controller circuit (Figure 10), and the extruder of the Kijenzi printer. These fans helped prevent any of these systems from overheating and all were equipped with dust-filters to minimize the dust that they expose their relative components that they are protecting. 


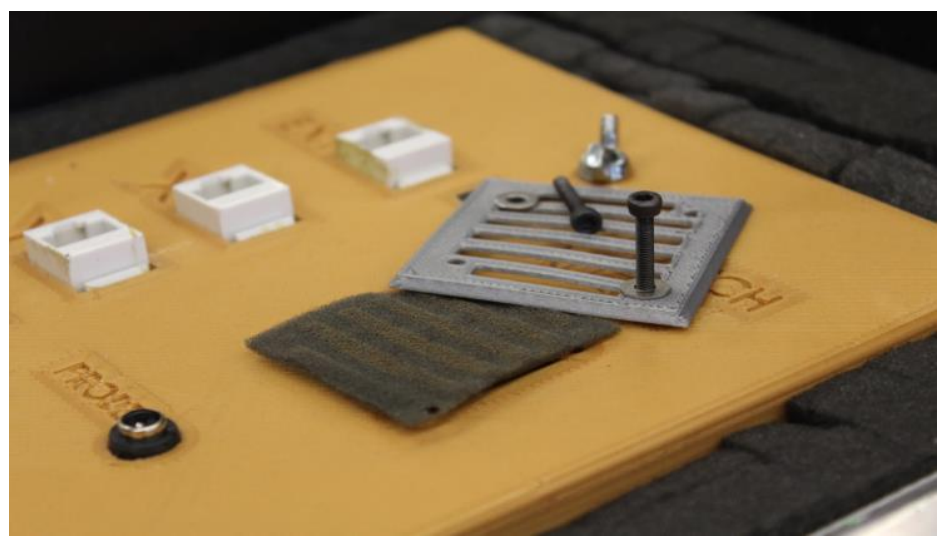

Figure 10. Fans with dust filters were effective at protecting electronics.

The addition of these fans, however, did not do anything to regulate the environmental conditions of the build volume. As the FFF process is sensitive to changes in temperature, humidity, and dust (all of which are also interdependent on the materials being printed), it is important these environmental controls be expanded in the future so as to regulate the quality of parts being 3-D printed.

\subsection{Evaluation of the Kijenzi 3-D Printer}

To assess these eight design elements and their effectiveness in providing the desired capabilities, a three-month trial program was conducted in western Kenya. Testing was not conducted in a humanitarian crisis, as it would be irresponsible to bring untested technology into such a setting [44-46]. Instead, we brought the Kijenzi 3-D printer to a range of health care facilities in peri-urban and rural areas and worked with local health care professionals to prototype devices commonly used in their practice.

\subsubsection{Kijenzi 3-D Printer's Ability to Make Useful Parts}

The Kijenzi printers made over 30 unique parts for use in hospital settings, including products as diverse as anatomical models, occupational therapy tools, orthopedic devices and replacement parts for medical machinery, some of which can be seen in Figure 11. 3-D printed parts were primarily fabricated out of polylactic acid (PLA), with the upgradeable Bed and Extruder Module, it was also able to successfully print parts with nylon, acrylonitrile butadiene styrene (ABS) and polyethylene terephthalate (PET). A standard calibration part (a $20 \times 20 \times 20 \mathrm{~mm}$ cube) was evaluated for accuracy and found to be $\pm 0.1 \mathrm{~mm}$ on $\mathrm{x}, \mathrm{y}$ and $\pm 0.1 \mathrm{~mm}$ on $\mathrm{z}$.

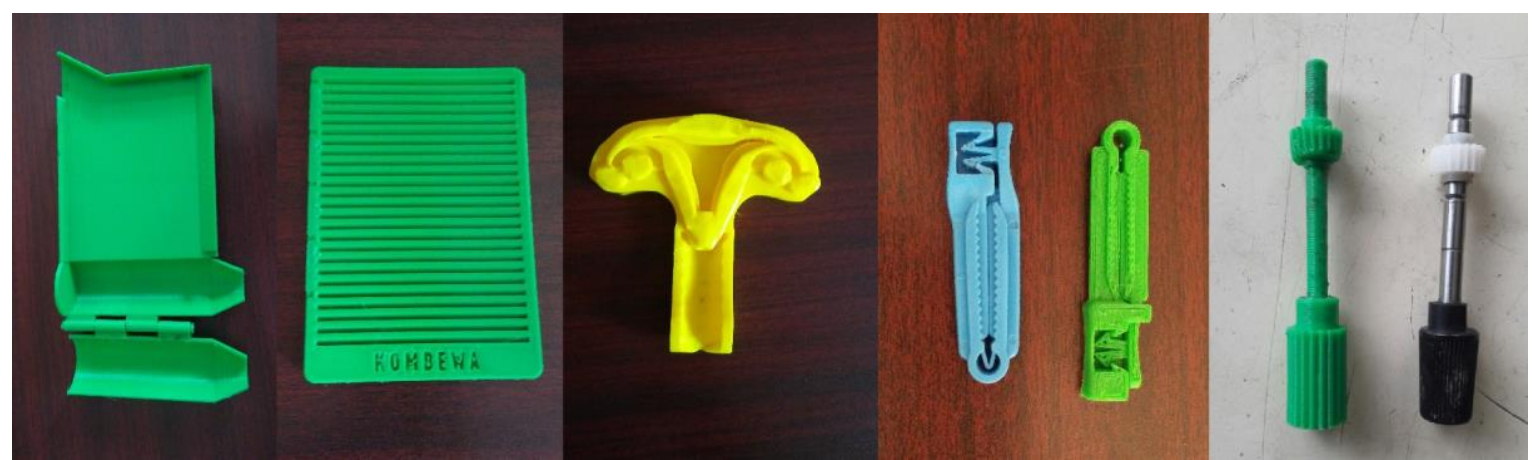

Figure 11. Examples of 3-D-printed medical parts created by the Kijenzi printer include, (from left to right), a pill sorter, a slide dryer, a uterine model, a replica of an umbilical cord clamps, and a replacement knob for a microscope. 
It is reasonable to conclude that the Kijenzi could print with nearly all of the commercial thermoplastics typically used in FFF 3-D printing including, polycarbonate (PC), high impact polystyrene (HIPS), polyethylene terephthalate glycol-modified (PETG), polyvinyl alcohol (PVA), nGen (a branded filament made up of the copolyester Eastman Amphor AM3300 3D polymer), t-glase (a branded polyester resin filament), copolymers, and various composites made from a base polymer and then wood, bamboo, coffee, linen, carbon fiber, metal powder, etc. However, these four materials (PLA, PET, ABS, and nylon) were sufficient for the Kijenzi to be able to print most of the parts that were requested by Kisumu medical professionals during the pilot program. Those parts that were not able to be 3-D printed on the Kijenzi-such as a leg prosthesis, scalpels, or humidifier filters-represent parts that would also be unprintable on any other desktop FFF 3-D printer due to size, resolution, and material properties respectively.

In addition, to the commercialized 3-D printing filaments, there is also a growing body of literature on the ability of FFF to use waste plastic/recycled plastic filament such as PLA [47-50], high density polyethylene (HDPE) [51-53], ABS [53-55], as well as waste wood composites [56] and carbon fiber reinforced composites [57]. This has the potential to reduce the costs of 3-D printing further and make the accessibility for 3-D printing feedstock greater in a disaster situation as only a recyclebot (waste plastic 3-D printer filament extruder [51]) would be needed and solar-powered recyclebot systems have already been demonstrated [55]. However, these machines would also need to be redesigned to meet the challenges of the environment.

\subsubsection{Kijenzi 3-D Printer's Ability to Function Independently of Infrastructure}

The Kijenzi 3-D printer's full potential was realized when used together in a system within the 'swarm' of all five of the Kijenzi printers. The first of the five Kijenzi 3-D printers to fail to perform properly failed due to a mechanical switch, a spare component that was not brought to Kisumu. Thus, this printer instantly became a collection of components, modules, and assemblies that could be immediately swapped into other machines to keep them running while maintenance was being done or to increase their functionality, as some of the five printers had modules with varying capabilities. This swapping allowed for two levels of maintenance occurring at any given time-inter-module level maintenance and intra-module level maintenance. At the inter-module level, maintenance was quick and simple, as modules were traded between printers without the need for any tools, minimizing the amount of time any 3-D printer would be off-line. Maintenance occurring at the intra-module level was often more in-depth as these repairs typically required more intensive processes (rewiring, soldering, etc.) or the replacement of a component within the module. However, by having extra modules, these intra-module repairs could be conducted without requiring the printer to be offline and losing productivity time. Once the module was repaired, it would just become the next spare module for a time when a different printer may require it.

In the rare event of mechanical part failures, this use of the printers in a swarm also allowed for the utilization of a RepRap's ability to fabricate many of its own spare parts. By using this swarm of quickly interchangeable modules and manufacturable components, all four of the remaining printers was kept running nearly continuously for two straight months.

The power supply units ensured that the printer could run continuously through minor power fluctuations and spikes, a common occurrence in western Kenya. These power supply units, however, were unable to save partially printed parts from being destroyed during power outages. As with any other 3-D printer, parts that were in the process of being printed during a power outage would have to be restarted (although recent work on process monitoring may solve this problem in the future [58]). Another solution for frequent electrical outages in any actual disaster setting, is to use an uninterruptable power supply, or firmware that can allow the Kijenzi printer to resume where it left off once the power resumes. The power supply unit was completely dependent upon the Kenyan electrical grid for power and thus would still require an alternative solution incorporating solar power to enable truly off-grid operation. This is a relatively minor challenge, as there have already been 
several demonstrable 3-D printing solutions that utilize a combination of solar and battery powered systems $[17,18,36]$ and a similar solution is already developed for future Kijenzi generations.

Finally, the addition of the on-board computer proved convenient for all the reasons hypothesized. However, as the Raspberry Pi did not have the computing ability to readily handle all of the operations involved in preparing a file for 3-D printing (i.e., 'slicing'), a more powerful on-board computer system should be included in future humanitarian 3-D printer designs to fully eliminate the need for a separate computer.

\subsubsection{Kijenzi 3-D Printer's Ability to Be Easily Transported}

The Kijenzi printer was very portable. It fit into a duffle bag/backpack and had a total mass of $12.5 \mathrm{~kg}$ making it easily taken as checked-luggage on every major airline [59]. When assembled, the collapsible printer had a cylindrical build volume with a base area of $490 \mathrm{~cm}^{2}$ and height of $15 \mathrm{~cm}$, which made its total build volume slightly larger than that typically found in off-the-shelf delta or non-delta 3-D printers.

The separable design also proved to be an effective strategy for transport. The design could be assembled or disassembled by one person in under $10 \mathrm{~min}$ without any tools. The Kijenzi printer was also generally durable enough to survive the vibration and impacts associated with air and motor-vehicle travel. The more fragile electronics were adequately protected in the casing and the aluminum frame, in addition to minimizing the weight of the design, also proved durable enough during travel. During all of the travels over the three month period, there was only one component of the motor modules that saw damage requiring redesign. This small cantilevered carriage was able to be reprinted on another printer and will be designed out of future Kijenzi models.

\subsubsection{Kijenzi 3-D Printer's Ability to Be Easily Used}

The modularity of the Kijenzi design, allowing modules to be added or removed without any tooling, did prove useful and allowed for simpler short-term repairs. The on-board computer also proved useful in making the printer easier to use, as there was never any need to configure a particular computer to the Kijenzi printer.

The usability of the Kijenzi printer-user interface may be the capability that still requires the most development. As the primary operators of the Kijenzi printers during the trial period were all at least tangentially involved in its development, it was not an accurate test of its usability for the general user. Further consideration to human computer interactions should be utilized in the future development of both its hardware and software.

There is also need for a printer with a more automated ability to maintain itself with minimal user intervention. An often-cited drawback of using delta-style 3-D printers is that they are complicated and cumbersome to calibrate and the Kijenzi printer is no exception in its current form. An auto-calibrating feature is in development and there are several open source methods available [60-64], as this is a much needed feature with how frequently recalibration needs to occur with frequent, rough transport of the printers.

\subsubsection{Kijenzi 3-D Printer's Ability to Withstand Harsh Environments}

Over the course of the trial period, the fan and dust filter kept the electronics of the system from overheating to the point of damage. During transport or adverse environmental conditions, the electronics case could be sealed to protect both the electronics and power supply unit. The only observed environmental damage to the printer itself was rusting that occurred on the guide rods on which the robotic arms moved. Comprised of A2 tool steel, these were the only components susceptible to corrosion in the humidity of western Kenya, as the rest of the frame was constructed using plastic components, aluminum square tubing and stainless steel fasteners. This rusting should be able to be improved with more regular greasing or the use of a different material such as stainless steel or aluminum. 
While these climate-control elements were useful for maintaining the ability of the Kijenzi printer to perform, there remains a need to develop a climate-controlled build-space. This will be a necessity in future iterations of the Kijenzi printer and other 3-D printers designed for humanitarian use. Not only do shifting environmental conditions affect the quality of the 3-D printed parts (requiring ever-optimized 3-D printer settings) but for medical applications there is a high importance of producing sterile parts. While the FFF process results in parts that are already sterile while printed (due to the molten thermoplastics being at least $180{ }^{\circ} \mathrm{C}$ ) [65], it is still necessary for its build environment to also be sterile to maintain that sterility.

\subsubsection{Kijenzi 3-D Printer's Ability to Be Procured for Minimal Cost}

The total cost of the basic Kijenzi 3-D printer is $\$ 521.32$ (Table 2) and the bill of materials available in ref [41]. A heated bed and on-board computer can be added to create the deluxe version that costs \$776.28. This puts the cost of the Kijenzi printer significantly below most of the top commercial desktop 3-D printers that currently represent the only option for humanitarian purposes [66]. It should be noted that there are FFF printers available on the market at lower prices but they are not nearly as functional as the Kijenzi, nor do they possess the first five desired capabilities listed in Table 1. Lastly, this was the cost to build only five printers with all off-the-shelf components and raw materials at full retail prices. At economies of scale, it is expected that the costs will be reduced significantly. Discussions with relief organizations such as Field Ready indicate that costs below $\$ 1,000$ would be acceptable [31]. If commercially manufactured, even the deluxe version would fall below that mark at retail price.

Table 2. Kijenzi 3-D printer modules costs to fabricate the basic and deluxe models.

\begin{tabular}{cccc}
\hline Modules & Quantity & Unit Cost (\$/Unit) & Module Cost (\$) \\
\hline Alpha-Beta-Gamma & 3 & 49.25 & 147.74 \\
Extruder & 1 & 106.56 & 106.56 \\
Control Box & 1 & 383.13 & 383.13 \\
Print Bed & 1 & 138.86 & 138.86 \\
\hline Removable Components & Kijenzi Deluxe & 776.28 \\
Internal Computer & -1 & 166.11 & \\
Heated bed assembly & -1 & 88.86 & -166.11 \\
\hline & Kijenzi Basic & -88.86 \\
\hline
\end{tabular}

\section{Conclusions}

Humanitarian NGOs currently exploring the capabilities of 3-D printing to solve logistics issues are forced to use desktop 3-D printers that are not suitable solutions to the challenges that they face. By examining existing literature regarding 3-D printing in humanitarian or remote contexts, this study found the need for six key capabilities of a 3-D printer appropriate for these contexts: (1) it must make useful parts; (2) it must function independent of infrastructure; (3) it must be easily transported; (4) it must be easily used; (5) it must be able to withstand harsh environments; and (6) it must be able to be procured for minimal costs. In an effort to build a 3-D printer for humanitarian applications, this study identified eight key design elements to incorporate into a prototype and how they related to the six desired capabilities. This prototype, the Kijenzi printer, was taken to a western Kenya hospital system and tested for two months.

The Kijenzi was found to be able to manufacture the same range of geometries and materials as any other commercially available 3-D printers, while still achieving unique durability and portability due to Kijenzi's ability to separate into different modules during travel. This modularity also allowed for quick and simplified upgrades or repairs when various modules failed and resulted in a new method of pursuing reliability with 3-D printing. By not viewing the 3-D printer as a singular machine 
but rather as a part of a system of several 3-D printers and 3-D printer modules, the entire 3-D printer swarm can be optimized to maximize the productivity of all printers and minimize the amount of down-time required for maintenance.

By paying careful attention to protecting the electronics of the system computer with sturdy casing, protective power supply and improved airflow, the electronics of the Kijenzi printer were made suitable for travel and use in adverse environments. The autonomy of the prototype was further improved by integrating an on-board computer and touchscreen into its electronics. However, the Kijenzi printer still requires an improved power sourcing methodology to overcome frequent power outages or contexts in which no grid-power is available. Solar power and battery systems must be integrated into future designs to further decrease the Kijenzi's reliance on reliable infrastructure.

There still remains a great need to improve the overall usability of the Kijenzi, as nearly all testing of the 3-D printer was conducted by people who were familiar with 3-D printing and a part of the prototype's development. Special consideration must be given to human-computer interaction as the development of Kijenzi moves forward and several maintenance-related operations (such as calibration) should be automated in order to reduce the level of technical expertise required to use the 3-D printer. Future iterations of the Kijenzi should also include mechanisms to control the environment of the build space, so that quality of the parts produced can be maintained without requiring user expertise to account for changes in the environment.

The Kijenzi represents an early foundation in developing a 3-D printer that is able to meet the capabilities required for rapid manufacturing in a disaster response. The eight elements incorporated into the design of the Kijenzi were all found to be beneficial in achieving the desired capabilities, however, these eight elements alone were found to be insufficient to create a 3-D printer fully ready for deployment. Future work must be done on the Kijenzi design and with our commitment to open-source development, it is hopeful that others will build upon the work presented here so that the technology may reach a level of maturity necessary for effectively addressing the many challenges associated with humanitarian efforts.

Acknowledgments: This work was partially supported by Pennsylvania State University and Fulbright Finland.

Author Contributions: Benjamin L. Savonen, Tobias J. Mahan, Maxwell W. Curtis and Jared W. Schreier conceived and designed the experiments; Benjamin L. Savonen, Tobias J. Mahan and Jared W. Schreier performed the experiments; Benjamin L. Savonen, Joshua M. Pearce and John K. Gershenson analyzed the data; and Benjamin L. Savonen, John K. Gershenson and Joshua M. Pearce wrote the paper. All authors have read and approved the final manuscript.

Conflicts of Interest: The authors declare no conflict of interest. The founding sponsors had no role in the design of the study, in the collection, analyses, or interpretation of data, in the writing of the manuscript, or in the decision to publish the results.

\section{References}

1. Development Initiatives. Global Humanitarian Assistance Report 2017; Development Initiatives: Bristol, UK, 2017.

2. Loy, J.; Tatham, P.; Healey, R.; Tapper, C.L. 3D Printing Meets Humanitarian Design Research: Creative Technologies in Remote Regions. Creative Technol. Multidiscip. Appl. 2016, 54-75. [CrossRef]

3. Sniderman, B.; Baum, P.; Rajan, V. 3D Opportunity for Life: Additive Manufacturing Takes Humanitarian Action. Deloitte Rev. Available online: https:/ / www2.deloitte.com/insights/us/en/deloitte-review /issue19/3d-printing-for-humanitarian-action.html (accessed on 12 October 2017).

4. De la Torre, N.; Espinosa, M.M.; Domínguez, M. Rapid Prototyping in Humanitarian Aid to Manufacture Last Mile Vehicles Spare Parts: An Implementation Plan. Hum. Factors Ergon. Manuf. Serv. Ind. 2016, 26, 533-540. [CrossRef]

5. James, E.; Gilman, D. Shrinking the Supply Chain: Hyperlocal Manufacturing and 3D Printing in Humanitarian Response; OCHA Policy and Studies Series; OCHA: New York, NY, USA, 2015; Volume 14. 
6. Sells, E.; Bailard, S.; Smith, Z.; Bowyer, A.; Olliver, V. RepRap: The Replicating Rapid Prototyper-Maximizing Customizability by Breeding the Means of Production. In Proceedings of the World Conference on Mass Customization and Personalization, Cambridge, MA, USA, 7-10 October 2007.

7. Jones, R.; Haufe, P.; Sells, E.; Iravani, P.; Olliver, V.; Palmer, C.; Bowyer, A. RepRap-the Replicating Rapid Prototyper. Robotica 2011, 29, 177-191. [CrossRef]

8. Bowyer, A. 3D Printing and Humanity's First Imperfect Replicator. 3D Print. Addit. Manuf. 2014, 1, 4-5. [CrossRef]

9. Pearce, J.M.; Blair, C.M.; Laciak, K.J.; Andrews, R.; Nosrat, A.; Zelenika-Zovko, I. 3-D printing of open source appropriate technologies for self-directed sustainable development. J. Sustain. Dev. 2010, 3, 17-29. [CrossRef]

10. Tatham, P.; Loy, J.; Peretti, U. Three Dimensional Printing-A Key Tool for the Humanitarian Logistician? J. Humanit. Logist. Supply Chain Manag. 2015, 5, 188-208. [CrossRef]

11. Wittbrodt, B.T.; Glover, A.G.; Laureto, J.; Anzalone, G.C.; Oppliger, D.; Irwin, J.L.; Pearce, J.M. Life-cycle economic analysis of distributed manufacturing with open-source 3-D printers. Mechatronics 2013, 23, 713-726. [CrossRef]

12. Petersen, E.E.; Pearce, J. Emergence of Home Manufacturing in the Developed World: Return on Investment for Open-Source 3-D Printers. Technologies 2017, 5, 7. [CrossRef]

13. Gwamuri, J.; Wittbrodt, B.; Anzalone, N.; Pearce, J. Reversing the Trend of Large Scale and Centralization in Manufacturing: The Case of Distributed Manufacturing of Customizable 3-D-Printable Self-Adjustable Glasses. Chall. Sustain. 2014, 2, 30-40. [CrossRef]

14. Wittbrodt, B.; Laureto, J.; Tymrak, B.; Pearce, J. Distributed Manufacturing with 3-D Printing: A Case Study of Recreational Vehicle Solar Photovoltaic Mounting Systems. J. Frugal Innov. 2015, 1, 1-7. [CrossRef]

15. Tanikella, N.G.; Savonen, B.L.; Gershenson, J.K.; Pearce, J.M. Viability of distributed manufacturing of bicycle components with 3-D printing: CEN standardized polylactic acid pedal testing. J. Humanit. Eng. 2017, 5, 8-17.

16. James, E.; James, L. 3D Printing Humanitarian Supplies in the Field. Humanit. Exch. 2016, 66, $43-45$.

17. Franco, D.; Khan, K.Y.; Gauchia, L.; Pearce, J.M. High-Efficiency Solar-Powered 3-D Printers for Sustainable Development. Machines 2016, 4, 3. [CrossRef]

18. King, D.L.; Babasola, A. Mobile open-source solar-powered 3-D printers for distributed manufacturing in off-grid communities. Chall. Sustain. 2014, 2, 18-27. [CrossRef]

19. International Federation of Red Cross and Red Crescent Societies. Emergency Items Catalogue. Available online: http:/ /itemscatalogue.redcross.int/ (accessed on 4 February 2018).

20. Wong, J.Y.; Pfahnl, A.C. 3D Printing of Surgical Instruments for Long-Duration Space missions. Aviat. Space Environ. Med. 2014, 85, 758-763. [CrossRef] [PubMed]

21. McBride, A. 3D Printing Takes Emergency Response to Another Level. Policy and Practice Blog, 2014. Available online: https:/ / policy-practice.oxfam.org.uk/blog/2014/05/3d-printing-takes-emergency-responseto-another-level (accessed on 4 February 2018).

22. Ott, D. Can Digital Fabrication Revolutionise Humanitarian Action? ICRC Blog, 2016. Available online: http:/ /blogs.icrc.org/gphi2/2016/02/22/can-digital-fabrication-revolutionize-humanitarian-action/ (accessed on 4 February 2018).

23. Scott, C. ICRC Enable Makeathon Endeavors to Help People with Disabilities in Remote Areas through 3D Printing and other Technologies. 3D Print, 2015. Available online: https://3dprint.com/tag/icrc/ (accessed on 4 February 2018).

24. Liaw, C.Y.; Guvendiren, M. Current and Emerging Applications of 3D Printing in Medicine. Biofabrication 2017, 9, 024102. [CrossRef] [PubMed]

25. Gregory, M.; Hameedaldeen, S.A.; Intumu, L.M.; Spakousky, J.J.; Toms, J.B.; Steenhuis, H.J. 3D Printing and Disaster Shelter Costs. In Proceedings of the 2016 Portland International Conference for Management of Engineering and Technology, Honolulu, HI, USA, 4-8 September 2016; pp. 712-720.

26. Angela, W.Y.; Khan, M. On-Demand Three-Dimensional Printing of Surgical Supplies in Conflict Zones. J. Trauma Acute Care Surg. 2015, 78, 201-203.

27. Michaels, R.E.; Pearce, J.M. 3-D printing open-source click-MUAC bands for identification of malnutrition. Public Health Nutr. 2017, 20, 2063-2066. [CrossRef] [PubMed]

28. Field Ready. Available online: http:/ / www.fieldready.org/ (accessed on 1 February 2018).

29. Refugee Open Ware. Available online: http://www.row3d.org/ (accessed on 1 February 2018). 
30. Saripalle, S.; Maker, H.; Bush, A.; Lundman, N. 3D Printing for Disaster Preparedness: Making Life-Saving Supplies on-Site, on-Demand, on-Time. In Proceedings of the IEEE Global Humanitarian Technology Conference, Seattle, WA, USA, 13-16 October 2016; pp. 205-208.

31. James, E. Functional and Technical Specifications for Field Grade 3D Printers Intended for Use in Humanitarian Contexts. Unpublished work. 2016.

32. Kovács, G.; Tatham, P. Responding to Disruptions in the Supply Network-From Dormant to Action. J. Bus. Logist. 2009, 30, 215-229. [CrossRef]

33. Bhatia, S.K.; Ramadurai, K.W. 3D Printing of Medical Devices and Supplies. In 3D Printing and Bio-Based Materials in Global Health; Springer: Berlin, Germany, 2017; pp. 63-93.

34. Meisel, N.A.; Williams, C.B.; Ellis, K.P.; Taylor, D. Decision Support for Additive Manufacturing Deployment in Remote or Austere Environments. J. Manuf. Technol. Manag. 2016, 27, 898-914. [CrossRef]

35. Wong, J.Y. Applications of 3D Printing in Austere Environments. Aerosp. Med. Hum. Perform. 2016, 87, 423-425. [CrossRef] [PubMed]

36. Wong, J.Y. Ultra-Portable Solar-Powered 3D Printers for Onsite Manufacturing of Medical Resources. Aerosp. Med. Hum. Perform. 2015, 86, 830-834. [CrossRef] [PubMed]

37. Wohlers Associates Inc. Wohlers Report 2016: 3D Printing and Additive Manufacturing State of the Industry Annual Worldwide Progress Report; Wohlers Associates Inc.: Fort Collins, CO, USA, 2016.

38. Anzalone, G.C.; Wijnen, B.; Pearce, J.M. Multi-material additive and subtractive prosumer digital fabrication with a free and open-source convertible delta RepRap 3-D printer. Rapid Prototyp. J. 2015, 21, 506-519. [CrossRef]

39. Tanikella, N.G.; Wittbrodt, B.; Pearce, J.M. Tensile strength of commercial polymer materials for fused filament fabrication 3D printing. Additive Manuf. 2017, 15, 40-47. [CrossRef]

40. Rundle, G. A Revolution in the Making; Simon and Schuster: New York, NY, USA, 2014.

41. Open Science Framework. Available online: https:/ / osf.io/pzxea/ (accessed on 12 February 2018).

42. Cruz Sanchez, F.A.; Boudaoud, H.; Muller, L.; Camargo, M. Towards a standard experimental protocol for open source additive manufacturing: This paper proposes a benchmarking model for evaluating accuracy performance of 3D printers. Virtual Phys. Prototyp. 2014, 9, 151-167. [CrossRef]

43. Raspbian Stretch. Available online: https://www.raspberrypi.org/downloads/raspbian/ (accessed on 26 February 2018).

44. Sandvik, K.B.; Jacobsen, K.L.; McDonald, S.M. Do no harm: A taxonomy of the challenges of humanitarian experimentation. Int. Rev. Red Cross 2017, 1-26. [CrossRef]

45. Ramalingam, B.; Scriven, K.; Foley, C. Innovations in International Humanitarian Action. In Proceedings of the ALNAP 8th Review of Humanitarian Action, London, UK, 13 July 2009.

46. Betts, A.; Bloom, L. Humanitarian Innovation: The State of the Art; OCHA Policy and Studies Series; OCHA: New York, NY, USA, 2014; Volume 9.

47. Cruz Sanchez, F.A.; Lanza, S.; Boudaoud, H.; Hoppe, S.; Camargo, M. Polymer Recycling and Additive Manufacturing in an Open Source context: Optimization of processes and methods. In Proceedings of the Annual International Solid Freeform Fabrication Symposium (ISSF), Austin, TX, USA, 10-12 August 2015; pp. 1591-1600.

48. Cruz Sanchez, F.A.; Boudaoud, H.; Hoppe, S.; Camargo, M. Polymer recycling in an open-source additive manufacturing context: Mechanical issues. Addit. Manuf. 2017, 17, 87-105. [CrossRef]

49. Anderson, I. Mechanical Properties of Specimens 3D Printed with Virgin and Recycled Polylactic Acid. 3D Print. Addit. Manuf. 2017, 4, 110-115. [CrossRef]

50. Pakkanen, J.; Manfredi, D.; Minetola, P.; Iuliano, L. About the Use of Recycled or Biodegradable Filaments for Sustainability of 3D Printing. In Sustainable Design and Manufacturing; Smart Innovation, Systems and Technologies; Springer: Cham, Switzerland, 2017; pp. 776-785.

51. Baechler, C.; DeVuono, M.; Pearce, J.M. Distributed recycling of waste polymer into RepRap feedstock. Rapid Prototyp. J. 2013, 19, 118-125. [CrossRef]

52. Chong, S.; Pan, G.-T.; Khalid, M.; Yang, T.C.-K.; Hung, S.-T.; Huang, C.-M. Physical Characterization and Pre-assessment of Recycled High-Density Polyethylene as 3D Printing Material. J. Polym. Environ. 2017, 25, 136-145. [CrossRef] 
53. Mohammed, M.I.; Mohan, M.; Das, A.; Johnson, M.D.; Badwal, P.S.; McLean, D.; Gibson, I. A low carbon footprint approach to the reconstitution of plastics into 3D-printer filament for enhanced waste reduction. KnE Eng. 2017, 2, 234-241. [CrossRef]

54. Mohammed, M.I.; Das, A.; Gomez-Kervin, E.; Wilson, D.; Gibson, I. EcoPrinting: Investigating the Use of $100 \%$ Recycled Acrylonitrile Butadiene Styrene (ABS) for Additive Manufacturing. Solid Freeform Fabrication 2017. In Proceedings of the 28th Annual International Solid Freeform Fabrication Symposium, Austin, TX, USA, 7-9 August 2017; Available online: http:/ / sffsymposium.engr.utexas.edu/sites/default/ files/2017/Manuscripts/EcoprintingInvestigatingtheUseof100Recycle.pdf (accessed on 3 March 2018).

55. Zhong, S.; Pearce, J.M. Tightening the loop on the circular economy: Coupled distributed recycling and manufacturing with recyclebot and RepRap 3-D printing. Resour. Conserv. Recycl. 2018, 128, 48-58. [CrossRef]

56. Pringle, A.M.; Rudnicki, M.; Pearce, J. Wood Furniture Waste-Based Recycled 3-D Printing Filament. For. Prod. J. 2018. [CrossRef]

57. Tian, X.; Liu, T.; Wang, Q.; Dilmurat, A.; Li, D.; Ziegmann, G. Recycling and remanufacturing of 3D printed continuous carbon fiber reinforced PLA composites. J. Clean. Prod. 2017, 142, 1609-1618. [CrossRef]

58. Nuchitprasitchai, S.; Roggemann, M.; Pearce, J.M. Three Hundred and Sixty Degree Real-Time Monitoring of 3-D Printing Using Computer Analysis of Two Camera Views. J. Manuf. Mater. Process. 2017, 1, 2. [CrossRef]

59. Gavein, L. Checked Baggage Allowances for Major Airlines: A simple Guide. Sky Scanner. Available online: https://www.skyscanner.net/news/tips/check-in-luggage-size-and-weight-restrictions/ (accessed on 4 February 2018).

60. Hsieh, C.T. Investigation of Delta Robot 3D Printer for a Good Quality of Printing. Appl. Mech. Mater. 2017, 870, 164-169. [CrossRef]

61. Celi, R.; Sempértegui, A.; Morocho, D.; Loza, D.; Alulema, D.; Proaño, M. Study, design and construction of a 3D printer implemented through a delta robot. In Proceedings of the 2015 CHILEAN Conference on Electrical, Electronics Engineering, Information and Communication Technologies (CHILECON), Santiago, Chile, 28-30 October 2015; pp. 717-722.

62. Soriano Heras, E.; Blaya Haro, F.; de Agustín del Burgo, J.M.; Islán Marcos, M.E. Plate auto-level system for fused deposition modelling (FDM) 3D printers. Rapid Prototyp. J. 2017, 23, 401-413. [CrossRef]

63. Wachlin, E.; Southerton, L. MOST Delta Autobed Leveling Appropedia. Available online: http://www. appropedia.org/MOST_Delta_Auto_Bed_Leveling (accessed on 5 February 2018).

64. Johann; FSR (Force Sensing Resistor). Reprap.org. Available online: http:/ / reprap.org/wiki/FSR (accessed on 5 February 2018).

65. Rankin, T.M.; Giovinco, N.A.; Cucher, D.J.; Watts, G.; Hurwitz, B.; Armstrong, D.G. Three-dimensional printing surgical instruments: Are we there yet? J. Surg. Res. 2014, 189, 193-197. [CrossRef] [PubMed]

66. 3D Hubs. 2018 3D Printer Guide. Available online: https://www.3dhubs.com/best-3d-printer-guide (accessed on 5 February 2018). 